\title{
Um estudo experimental do processamento de metáforas do português brasileiro
}

\section{An experimental study on Brazilian Portuguese metaphor processing}

\begin{abstract}
Antonio João Carvalho Ribeiro
Grupo de Estudos e Laboratório em Psicolinguística Experimental - GEPEX

Universidade Federal Fluminense, Niterói, Rio de Janeiro / Brasil

ajcarvalhoribeiro@gmail.com

Adiel Queiroz Ricci

Grupo de Estudos e Laboratório em Psicolinguística Experimental - GEPEX

Universidade Severino Sombra, Vassouras, Rio de Janeiro / Brasil

adielricci@gmail.com
\end{abstract}

Resumo: Um estudo experimental do processamento psicolinguístico de metáforas nominais do português brasileiro (X é um Y), p. ex., "Irene é um furacão", foi realizado com o objetivo de evidenciar, a partir de tempos de leitura $(R T S)$, a compreensão de expressões familiares, highapt ("bem construídas") e cujo veículo se acha convencionalizado. $\mathrm{Na}$ primeira fase da pesquisa, realizaram-se dois norming studies ("estudos normativos") com vistas ao ranqueamento de metáforas nominais (p. ex. "Algumas mulheres são furacões") em relação a familiaridade, aptness ("adequação") e convencionalidade. Na segunda fase da pesquisa, um experimento de leitura automonitorada (self-paced, non-cumulative, moving-window reading) foi conduzido, recorrendo, para a composição dos estímulos, às metáforas, p. ex., "Irene é um furacão", que alcançaram, nos estudos normativos da primeira fase, ratings (ou "classificações") de "muito familiares", "very high-apt" e "altamente convencionalizadas". Evidências do português brasileiro em favor do processamento direto de metáforas foram obtidas, conforme preconiza o modelo de Class- 
inclusion, de Glucksberg e Keysar (1990), pois não se revelaram diferenças significativas entre os $R T S$ médios nas três condições: "metáfora", "literal" e "declaração literal de inclusão em classe", em contraposição aos achados de Janus e Bever (1985), que observaram tempos de leitura de metáforas novas significativamente maiores do que os de expressões literais, conforme as predições do Modelo Pragmático Padrão de processamento indireto.

Palavras-chave: processamento psicolinguístico da metáfora; classinclusion; dual reference; norming studies; compreensão de linguagem figurada; português brasileiro.

Abstract: An experimental study on the psycholinguistic processing of Brazilian Portuguese attributive metaphors (X is a Y), e.g., "Irene é um furacão" ("Irene is a hurricane"), was carried out with the aim of highlighting, from reading times (RTs), the understanding of familiar, highapt ("well-built") expressions and the vehicle of which is conventionalized. In the first phase of the research, two norming studies were carried out aiming at the ranking of attributive metaphors, e.g. "Algumas mulheres são furacões" ("Some women are hurricanes"), regarding familiarity, aptness and conventionality. In the second phase of the research, a self-paced, noncumulative, moving-window reading experiment was conducted, using, for the composition of the stimuli, the metaphors, e.g. "Irene é um furacão", that have reached, in the normative studies of the first phase, ratings of "very familiar", "very high-apt" and "highly conventionalized". Brazilian Portuguese evidences in favor of direct processing of metaphors were obtained, as recommended by the Class-inclusion model of Glucksberg and Keysar (1990), since there were no significant differences between the mean RTs in the three conditions: "Metaphor", "Literal" and "Literal Declaration of Class Inclusion". In contrast to the findings of Janus and Bever (1985), who observed reading times of new metaphors significantly larger than those of literal expressions, according to the predictions of the Standard Pragmatic Model of indirect processing.

Keywords: psycholinguistic processing of metaphor; class-inclusion; dual reference; norming studies; figurative language comprehension; brazilian portuguese.

Recebido em: 8 de dezembro de 2017.

Aprovado em: 16 de março de 2017. 


\section{Introdução}

Este artigo pretende inserir o português brasileiro (PB) na literatura sobre compreensão de metáforas, polarizada, segundo Glucksberg (2003), entre modelos de processamento indireto, cujos pressupostos se têm revelado hipóteses testáveis, e processamento direto, com base em evidências empíricas da interferência das variáveis "Familiaridade", "Aptness" ("eficácia", "adequação") e "Convencionalidade". Para tanto, reportamos aqui os resultados da pesquisa em que nos envolvemos nos últimos dois anos, investigando a compreensão de metáforas que se acham convencionalizadas no $\mathrm{PB}$, sugestivos de processamento direto segundo o modelo de Class-inclusion de Glucksberg e Keysar (1990). ${ }^{1}$

$\mathrm{Na}$ fase inicial da pesquisa, foram realizados dois pré-testes - norming studies nos quais os participantes ranquearam expressões metafóricas, por exemplo, "Algumas mulheres são furacões", em Familiaridade, Aptness e Convencionalidade. ${ }^{2} \mathrm{Na}$ literatura da área, são chamados de norming studies (BLASKO; CONNINE, 1993; BOWDLE; GENTNER, 2005; DULCINATI et al., 2014), ou norming pre-tests (JONES; ESTES, 2006), ou ainda rating experiments (THIBODEAU; DURGIN, 2011), ou, simplesmente, de rating tasks (HARRIS, 1976), os instrumentos concebidos para avaliar expressões metafóricas. O objetivo dos ranqueamentos foi o de selecionar expressões, entre as que receberam os ratings mais altos em ambos, como norteadoras da construção dos estímulos do experimento de leitura automonitorada conduzido na fase subsequente. Por exemplo, os ratings altos atribuídos a "Algumas mulheres são furacões" basearam a construção do estímulo "Irene é um furacão" que, inserido em contextos (parágrafos) apropriados, permitiria interpretação metafórica (se Irene é uma mulher agitada) ou literal (se Irene é o furacão que atingiu o Caribe e os EUA em 2011).

A opção por utilizar metáforas nominais - do tipo X é um $\mathrm{Y}$-em que $\mathrm{X}$ é o tópico e Y é o veículo, nos exemplos acima, respectivamente,

\footnotetext{
${ }^{1}$ A pesquisa em questão, orientada pelo primeiro autor, foi conduzida pelo segundo, como parte dos requisitos de obtenção, por esse último, do título de Mestre em Linguística (RICCI, 2016). Aprovação pelo CEP da USS - RJ, CAAE 50572215.80000.5290, parecer 1.412.627, em 22 fev. 2016.

${ }^{2}$ Os resultados dos referidos norming studies foram apresentados no XXXI ENANPOLL (RIBEIRO et al., 2016)
} 
"Algumas mulheres" e "Irene" / "furacões" e "furacão", deve-se ao fato de a maioria dos experimentos que se acham descritos na literatura focalizar essa forma (DULCINATI et al., 2014, p. 72).

Finalmente, a decisão de propor uma tarefa de leitura automonitorada de expressões do $\mathrm{PB}$ em contextos diversos visou a superar as fragilidades metodológicas apontadas por Janus e Bever (1985) nos experimentos conduzidos até então - sustentando (cf. CLARK; LUCY, 1975; GIBBS JR., 1979, 1981) ou refutando (cf. ORTONY et al., 1978; GLUCKSBERG; GILDEA; BOOKIN, 1982) o que se convencionou chamar de Modelo Pragmático Padrão de processamento indireto da metáfora (cf. SEARLE, 1993 [1979]; GRICE, 1975) - nos quais não se preveem contextos, ou tempos de leitura são medidos ao final da apresentação dos estímulos. Janus e Bever (1985) mediram tempos de leitura dos fragmentos críticos de expressões contextualizadas, isto é, dos sintagmas nominais que contêm o veículo - locus do "Problema do Reconhecimento" do significado metafórico - e observaram que metáforas "novas" tomaram, em média, tempos de leitura significativamente maiores do que expressões equivalentes de significado literal. Sendo assim, ofereceu-se, na literatura, o espaço que este estudo no PB busca ocupar: adotando as linhas mestras do experimento que foi conduzido por Janus e Bever (1985), oferecer achados cronométricos em proveito da tese do processamento direto de metáforas familiares, high-apt e cujo veículo acha-se convencionalizado.

\section{Revisão da literatura}

Tradicionalmente, na esteira da visão aristotélica, de que a metáfora é desviante da linguagem ordinária (GARRET, 2007), a interpretação metafórica é considerada como opcional (GLUCKSBERG, 2003; BOWDLE; GENTNER, 2005). No que se convencionou chamar de Modelo Pragmático Padrão (SPM), o processamento da metáfora (bem como o da linguagem figurada em geral) se dá em três estágios. Inicialmente, o ouvinte / leitor deriva o significado literal da expressão. No segundo estágio, ele verifica se a interpretação é apropriada no contexto do enunciado e deve ser aceita, ou não, como significado pretendido pelo locutor. Se implausível, a representação inicial é rejeitada, e chega-se ao terceiro estágio, o da busca por uma interpretação metafórica. Portanto, a malograda interpretação inicial do significado literal funciona como 
o "gatilho" que dispara a busca por um significado metafórico que dê conta do proferimento (SEARLE, 1993 [1979], p. 89-90). Sendo assim, metáforas nominais como, por exemplo, Some jobs are jails ("Alguns empregos são prisões") (exemplo retirado de GLUCKSBERG; KEYSAR, 1990; GLUCKSBERG, 1998, 2003) seriam reconhecidas como asserções que ferem a máxima da qualidade (GRICE, 1975), e uma maneira de compreendê-las passaria por sua conversão em símile, Some jobs are like jails ("Alguns empregos são como prisões"), declarações literais verdadeiras, posto que duas coisas quaisquer sempre podem ser semelhantes de inúmeras maneiras.

Entretanto, Glucksberg, Gildea e Bookin (1982) questionam a prioridade do significado literal / opcionalidade da interpretação metafórica, pressuposto do modelo SPM, a partir das evidências que obtiveram em uma série de experimentos de verificação de sentenças inspirados no teste de Stroop (1935). Stroop (1935) evidenciou a competição entre processos atencionais que permite capturar o automatismo das fases iniciais do processamento da leitura, traduzido em erros ou maiores tempos de reação ao se responder em que cor uma palavra (por exemplo, vermelho) está escrita, quando ela se acha impressa em outra cor (por exemplo, verde). Glucksberg, Gildea e Bookin (1982.) alegam que as metáforas que eles apresentaram aos participantes, p. ex., some surgeons are butchers ("alguns cirurgiões são açougueiros") tomaram mais tempo para serem julgadas como falsas do que as metáforas "embaralhadas", p. ex., some jobs are butchers ("alguns empregos são açougueiros"), porque os significados metafóricos disponíveis nas metáforas, mas não nas metáforas embaralhadas, interferiram no julgamento do significado literal dessas expressões. Recorrendo à lógica do efeito Stroop, ou da "compulsão" por ler a palavra quando se é instado a dizer o nome da cor em que a ela está escrita, Glucksberg, Gildea e Bookin (1982) refutam o modelo SPM, segundo o qual se cogitam interpretações metafóricas apenas quando os significados literais se mostram intratáveis, sustentando que interpretações metafóricas não podem ser inibidas ou, em suas próprias palavras, que o significado metafórico não pode ser ignorado.

De acordo com Glucksberg e colaboradores (GLUCKSBERG; KEYSAR, 1990; GLUCKSBERG, 1998; GLUCKSBERG, 2003), falham as diversas teorias (cf. TVERSKY, 1977; ORTONY, 1993 [1979]) que tratam metáforas como comparações implícitas porque, em comparações literais, a equação "X é como um Y" é bidirecional, p. ex.: copper is like tin 
ou tin is like cooper ("cobre é como estanho" ou "estanho é como cobre"), coffee is like tea ou tea is like coffee ("café é como chá" ou "chá é como café"), enquanto, em metáforas, os elementos não podem ser comutados, $p$. ex.: some jobs are jails, mas não *some jails are jobs ("alguns empregos são prisões", mas não “*algumas prisões são empregos"), sermons are sleeping pills, mas não * sleeping pills are sermons ("sermões são soníferos", mas não "*soníferos são sermões"). A aparente reversibilidade dos elementos da metáfora produz uma nova expressão, p. ex.: some surgeons are butchers ("alguns cirurgiões são açougueiros") e some butchers are surgeons ("alguns açougueiros são cirurgiões") diferem nas bases que sustentam a construção de cada uma delas.

De acordo com Glucksberg e colaboradores (GLUCKSBERG; KEYSAR, 1990; GLUCKSBERG, 1998), metáforas são o que aparentam ser: declarações de inclusão em classe, tanto quanto asserções literais de inclusão em categorias. A metáfora sermons are sleeping pills ("sermões são soníferos"), por exemplo, comporta-se como uma declaração de inclusão de sermons ("sermões") na categoria metafórica sleeping pills ("soníferos"), tal qual a asserção a tree is a plant ("uma árvore é um vegetal") inclui tree ("árvore") na classe plant ("vegetal") (GLUCKSBERG; KEYSAR, 1990, p. 12). É evidência, segundo eles, de que, em metáforas nominais, "X é um Y" expressa relação de inclusão em classe, e não de igualdade, a possibilidade de parafrasear, sem problemas, comparações metafóricas em metáforas (na forma paradigmática), p. ex.: my job is like a jail $\rightarrow$ my job is a jail ("meu emprego é como uma prisão $\rightarrow$ meu emprego é uma prisão"); ao passo que é impossível parafrasear comparações literais em declarações verdadeiras, p. ex.: bees are like hornets $\rightarrow$ *bees are hornets ("abelhas são como vespas $\rightarrow$ *abelhas são vespas") (GLUCKSBERG; KEYSAR, 1990, p. 7-11) ou my lawyer was like a shark $\rightarrow$ my lawyer was a shark ("meu advogado é como um tubarão $\rightarrow$ meu advogado é um tubarão"), mas não barracudas are like sharks $\rightarrow$ *barracudas are sharks" ("barracudas são como tubarões $\rightarrow$ *barracudas são tubarões”) (GLUCKSBERG, 1998, p. 41).

De acordo com o modelo teórico de Glucksberg e Keysar (1990) - Class-inclusion -, metáforas são compreendidas como declarações de inclusão em classes, ou categorias, nas quais os veículos metafóricos têm o que ele chama de Dual Reference ("dupla referência"). Por exemplo, shark refere um predador marinho (ou uma categoria deles) e também uma categoria abstrata de entes predatórios em geral à qual empresta $\mathrm{o}$ 
nome. Em my lawyer was a shark ("meu advogado era um tubarão") o veículo da expressão, (shark / "tubarão") estabelece uma relação taxonômica entre predador marinho e advogado, ambos abrigados em categoria abstrata de entes predatórios em geral que recebe o nome do membro prototípico: shark / "tubarão". Em síntese, metáforas cujos veículos referem categorias metafóricas convencionalizadas são processadas diretamente, tanto quanto asserções literais de inclusão em categoria, nos termos do modelo de Class-inclusion / Dual reference, em que a "dupla referência" provê explicação tanto para a "não reversibilidade da metáfora" quanto para a possibilidade de parafrasear comparações metafóricas em declarações, o que permite distinguir metáforas de comparações (GLUCKSBERG, 2003, p. 95). A par desses fatos, Glucksberg $(1998,2003)$ rechaça a hipótese de que metáforas seriam processadas a partir da conversão em símiles, amparado nos achados empíricos de Johnson (1996), de que metáforas na forma de declaração, p. ex.: my lawyer is a shark ("meu advogado é um tubarão") foram compreendidas mais rapidamente que símiles, my lawyer is like a shark ("meu advogado é como um tubarão"), embora essas contenham uma palavra (like / "como") mais do que aquelas.

Ao legitimar a possibilidade de o membro prototípico designar a categoria metafórica, Glucksberg e Keysar (1990, p. 8) alegam que diversas línguas se valem, rotineiramente, da estratégia para rotular categorias supraordenadas. Na língua de sinais americana, utilizamse sinais para itens básicos do mobiliário, chair ("cadeira"), table ("mesa"), bed ("cama") para referir categoria furniture ("mobília"). No birmanês, falado no sudeste da Ásia (Birmânia, Tailândia, Malásia e Singapura) recorre-se à dupla função de nomes que referem objetos altamente prototípicos e classes (DENNY, 1986; CRAIG, 1986 apud GLUCKSBERG; KEYSAR, 1990). Até mesmo em línguas não classificadoras, como o hebraico e o inglês, identificam-se exemplos da utilização de nomes prototípicos para designar categorias, como o sobrenome de um acusado de crimes de guerra, Demjanjuk, que, em Israel e artigos de jornais norte-americanos tornou-se a palavra para identificar "indivíduo comum capaz de cometer atos inomináveis" (SHINOFF, 1987 apud GLUCKSBERG; KEYSAR, 1990) -, ainda que John Demjanjuk, não tenha sido julgado, definitivamente, culpado dos crimes atribuídos ao sádico guarda do campo de concentração de Treblinka, na Polônia, chamado de "Ivan o Terrível". Em grande número 
de línguas indígenas do sudoeste dos Estados Unidos, há fartos exemplos do uso ocasional de nomes de membros prototípicos para rotular as categorias em que se incluem. Na língua hopi, o nome da espécie mais abundante, cottonwood, pode designar todas as árvores chamadas de deciduous trees, ou caducifólias ou de folhas "caducas", que perdem completamente as folhas no outono e no inverno (TRAGER, 1938 apud GLUCKSBERG; KEYSAR, 1990). E em shoshoni, a palavra para "águia” também é usada para aves de grande porte em geral (HAGE; MILLER, 1976 apud GLUCKSBERG; KEYSAR, 1990). Segundo Glucksberg e Keysar (1990), o princípio subjacente aos exemplos de dupla referência acima - tomar o membro que é prototípico para referir a categoria - explica o que se dá nas metáforas: toma-se o veículo para referir a categoria metafórica, abstrata, além de referir o ente real. Há casos em que a dupla referência do veículo das metáforas fica explícita, como, por exemplo, na fala de um espectador presente ao julgamento de John Demjanjuk, transcrita por Glucksberg e Keysar (1990, p. 8): I know his name is Demjanjuk, but I don't know if he is a Demjanjuk ("Eu sei que o nome é Demjanjuk, mas não sei se ele é um Demjanjuk"). E no exemplo oferecido por Glucksberg (2003, p. 94): Cambodia was Vietnam's Vietnam ("O Camboja foi o Vietnã do Vietnã"), em que, em inglês, a primeira menção a Vietnã refere o país, e a segunda menção (de Vietnã), a categoria abstrata supraordenada das intervenções militares desastrosas decorrentes do conflito armado no sudeste da Ásia (e viceversa em português).

Finalmente, no mapeamento do campo de pesquisas em psicolinguística da metáfora até então explorado, Glucksberg (2003) enfatiza as evidências dos experimentos de Blasko e Connine (1993) de crossmodal priming (no caso, priming semântico associado a uma tarefa de decisão lexical), de que ratings altos de familiaridade e aptness aceleram a ativação do significado metafórico do veículo de metáforas. Com isso, Glucksberg (2003) arrola, além da convencionalidade do veículo, o papel das variáveis Familiaridade e Aptness ("adequação ou eficácia da expressão") no acesso rápido ao significado metafórico e, portanto, tributárias do processamento direto de expressões metafóricas. 


\section{Experimento 1: norming study de Familiaridade e Convencionalidade}

O Experimento 1 objetivou avaliar a familiaridade dos participantes em relação às metáforas que foram construídas, para tal fim, pelo pesquisador, sendo familiaridade aqui entendida como familiaridade subjetiva, segundo a definição de Blasko e Connine (1993, p. 305): the perceived experience with the metaphor ("a sensação da experiência com a metáfora") ${ }^{3}$ Para além da obtenção de ratings de familiaridade das metáforas - em familiar e não familiar - estimou-se a convencionalidade das expressões, cujos veículos tiveram o significado figurado colhido em dicionários de prestígio do $\mathrm{PB} .{ }^{4}$ Para tanto, cada um dos participantes escolheu, entre três palavras, aquela que, de acordo com ele(a), capturava o significado que a expressão pretendia comunicar. A partir das respostas, verificou-se se o veículo (Y) evocara o significado figurado ou por extensão registrado nos dicionários consultados, permitindo, ou não, inferir se o mesmo se achava, ou não, convencionalizado no repertório dos indivíduos da amostra.

Participantes: 81 estudantes da Universidade Severino Sombra, em Vassouras - RJ, com idade entre 18 e 56 anos, sendo 16 do sexo masculino e 65 do feminino, todos falantes nativos de PB, jamais tendo colaborado em experimentos sobre compreensão de metáforas, participaram voluntariamente.

Materiais: 84 metáforas nominais (X é um Y) foram construídas, pelo pesquisador, sem repetições de veículos $(\mathrm{Y})$ ou tópicos $(\mathrm{X})$. Os tópicos das expressões foram modificados por "alguns(mas)" e tanto os tópicos $(\mathrm{X})$ quanto os veículos (Y) são substantivos concretos, de mesmo gênero, por exemplo: "Alguns carros são abacaxis". Com exceção de alguns tópicos (X), que são comuns de dois gêneros e alguns veículos, sobrecomuns, p. ex.: "Alguns motoristas são lesmas". Os significados figurados de todos os veículos (Y) acham-se registrados em pelo menos

\footnotetext{
${ }^{3}$ Em oposição a familiaridade objetiva, estimada com base na frequência metafórica, utilizando a ferramenta de pesquisa Google com corpus (THIBODEAU; DURGIN, 2011, p. 209).

${ }^{4}$ AULETE. Aulete Digital: o dicionário da língua portuguesa na internet; HOUAISS; VILLAR. Dicionário Houaiss da Língua Portuguesa, 3. ed. (2009); FERREIRA. Novo Aurélio século XXI: o Dicionário da Língua Portuguesa (1999); e a 6 a edição do FERREIRA. Miniaurélio: o Minidicionário da Língua Portuguesa (2004).
} 
dois dos dicionários consultados. E, tomadas literalmente, todas as expressões construídas são falsas.

Procedimentos: Em dias pré-determinados, grupos de participantes de, no máximo, 19, foram acomodados em uma das salas do Núcleo de Ensino Semipresencial da USS - $\mathrm{RJ}^{5}$ e, após firmarem o Termo de Consentimento Livre e Esclarecido, realizaram a tarefa proposta, em média, em 15 minutos. Cada um dos participantes sentou-se em frente a uma tela LCD de 17" que mostrava o formulário Google (Google Chrome sobre Windows 7) que continha as perguntas que deveriam responder (cada uma das telas conectada a um PC com teclado com fio ABNT2 e mouse USB óptico, com fio, de três botões e scroll). No cabeçalho de cada um dos blocos do formulário, imediatamente acima da expressão que tinham que julgar (familiar ou não familiar) os participantes podiam ler as instruções acerca do procedimento a ser seguido: "As expressões abaixo lhe são familiares?" "Você já as leu ou ouviu?" E, continuando: "Marque SIM (se for familiar) ou NÃO (se não for familiar)". E "Depois, tendo, ou não, ouvido ou lido a expressão, escolha uma palavra que você acredita que capture o seu significado".

Assim, foi possível estimar a convencionalidade do veículo (Y) de cada uma das metáforas, cujo significado figurado achava-se entre as opções, além de avaliar a qualidade da participação dos componentes da amostra, pois as outras opções referiam o significado literal da expressão ou o oposto do metafórico. Na distribuição das múltiplas escolhas, cuidou-se de alternar, dentro do formulário, as posições em que apareciam as opções (cf. excerto do formulário, na Figura 1). Dar respostas a todas as perguntas era obrigatório, impossibilitando que fossem deixadas em branco quando do envio do formulário via acesso à internet. E, ao final de cada sessão, os participantes puderam conhecer os objetivos do experimento e ter esclarecidas dúvidas que eventualmente tivessem.

${ }^{5}$ Núcleo de Ensino Semipresencial da Universidade Severino Sombra, em Vassouras $-\mathrm{RJ}$. 
Figura 1 - Excerto do formulário de Familiaridade

FAMILIARIDADE
As expressões abaixo Ihe são familiares? Você já as leu ou ouviu?
Marque SIM (se for familiar) ou NÃO (se não for familiar).
Depois, tendo, ou não, ouvido ou lido a expressão, escolha uma palavra que você acredita
que capture o seu significado.
1. Alguns carros são abacaxis. *
(Esta expressão Ihe é familiar?)
SIM
NÃO
Agora escolha uma palavra que capture o significado da expressão acima: *
COMPLICAÇÃO
FACILIDADE
FRUTO

\subsection{Experimento 2: norming study de Aptness $^{6}$ e Convencionalidade}

O Experimento 2 objetivou avaliar em aptness as expressões do conjunto de 84 metáforas cuja familiaridade foi julgada no Experimento 1. Atendendo à definição de aptness mais amplamente aceita: the extent to which the statement captures important features of the topic (cf. CHIAPPE et al., 2003, p. 97) ("o quanto a declaração captura as características importantes do tópico"), ${ }^{7}$ foi pedido aos participantes que dessem notas de 1 a 5 a cada uma das expressões, avaliando a sua eficácia em transmitir o significado que pretendem transmitir. Além disso, estimou-se, como foi feito no Experimento 1, a convencionalidade das expressões.

Participantes: 79 estudantes da Universidade Severino Sombra, em Vassouras - RJ, com idade entre 19 e 44 anos, sendo 28 do sexo masculino e 51 do feminino, todos falantes nativos de PB, jamais

\footnotetext{
${ }^{6}$ A versão, em português, de aptness, aqui, bem como nos formulários apresentados aos participantes, "eficácia", poderia ser "capacidade" ou "competência", "jeito", ou, até mesmo, "adequação" ou "a qualidade do que é apropriado ou adequado".

${ }^{7}$ Dulcinati et al. (2014, p. 74), advertem que se trata de uma propriedade da metáfora que tem recebido muitas definições diferentes.
} 
tendo colaborado em experimentos sobre compreensão de metáforas, participaram voluntariamente.

Materiais: As mesmas 84 metáforas nominais (X é um Y) mostradas aos participantes do Experimento 1.

Procedimentos: Em dias pré-determinados, grupos de participantes de, no máximo, 19, foram acomodados em uma das salas do Núcleo de Ensino Semipresencial da USS $-\mathrm{RJ}^{8} \mathrm{e}$, após firmarem o Termo de Consentimento Livre e Esclarecido, realizaram a tarefa proposta, em média, em 15 minutos. Cada um dos participantes sentou-se em frente a uma tela LCD de 17" que mostrava o formulário Google (Google Chrome sobre Windows 7) que continha as perguntas que deveriam responder (cada uma das telas conectada a um PC com teclado com fio ABNT2 e mouse USB óptico, com fio, de três botões e scroll). No cabeçalho de cada um dos blocos do formulário, imediatamente acima da expressão que tinham que julgar, os participantes podiam ler as instruções acerca do procedimento a ser seguido: "Dê uma nota de 1 a 5 a cada uma das expressões abaixo, avaliando a sua eficácia em transmitir o significado que pretendem transmitir", e "Depois, escolha uma palavra que você acredita que capture o seu significado". Tal qual no Experimento 1, foi possível estimar a convencionalidade do veículo (Y) de cada uma das metáforas, cujo significado figurado achava-se entre as opções, além de avaliar a qualidade da participação dos componentes da amostra, pois as outras opções referiam o significado literal da expressão ou o oposto do metafórico. Na distribuição das múltiplas escolhas, cuidouse de alternar, dentro do formulário, as posições em que apareciam as opções (cf. excerto do formulário, na Figura 2). Dar respostas a todas as perguntas era obrigatório, impossibilitando que fossem deixadas em branco quando do envio do formulário via acesso à internet. E, como no Experimento 1, ao final de cada sessão, os participantes puderam conhecer os objetivos do experimento e ter esclarecidas dúvidas que eventualmente tivessem.

\footnotetext{
${ }^{8}$ Nas mesmas dependências em que foi realizado o Experimento 1.
} 
Figura 2 - Excerto do formulário de Aptness

\begin{abstract}
APTNESS
Dê uma nota, de 1 a 5 , a cada uma das expressões abaixo, avaliando a sua eficácia em transmitir o significado que pretendem comunicar.

Depois escolha uma palavra que você acredita que capture o significado da expressão.

1. Alguns carros são abacaxis. *

$\begin{array}{lllll}1 & 2 & 3 & 4 & 5\end{array}$

Agora escolha uma palavra que capture o significado da expressão acima: * COMPLICAÇÃO

FACILIDADE

FRUTO
\end{abstract}

\title{
3.2 Resultados dos norming studies
}

Os resultados dos 2 norming studies contabilizaram um total de 26.880 julgamentos das 84 expressões metafóricas que foram construídas para esse fim: 13.608 julgamentos feitos pelos 81 participantes do Experimento 1 a respeito da "Familiaridade" e da "Convencionalidade" das metáforas; e outros 13.272, feitos pelo grupo de 79 participantes do Experimento 2, que as ranquearam em "Aptness" e "Convencionalidade" - em ambos os casos, com a finalidade de compor o conjunto de estímulos do experimento de leitura automonitorada que foi realizado na fase seguinte da pesquisa. A seleção das metáforas de rating mais alto em "Convencionalidade" baseou-se na média das estimativas obtidas nos 2 experimentos.

Considerando-se o indivíduo, familiaridade deve ser vista como uma variável discreta, envolvendo exclusivamente dois fatores, ou "sentimentos": um, de familiaridade com "algo", e outro de não familiaridade com "esse algo", se o que é percebido pelo indivíduo lhe parece, respectivamente, familiar ou não familiar. Porém, tomando grupos de indivíduos, é lícito admitir graus de familiaridade, tais como os ratings de "Familiaridade" obtidos entre os participantes do Experimento 1, que resultaram em metáforas "não familiares", "pouco familiares", "medianamente familiares", "familiares" e "muito familiares" reunidos na Tabela 1. 
Tabela 1 - Ratings de "Familiaridade" no Experimento 1

\begin{tabular}{ll}
\hline \multicolumn{1}{c|}{ Ratings das expressões } & \multicolumn{1}{c}{ Respostas SIM (\%) } \\
\hline Metáforas muito familiares & entre 80 e 100 \\
Metáforas familiares & igual ou maior que 60 e menor que 80 \\
Metáforas medianamente familiares & igual ou maior que 40 e menor que 60 \\
Metáforas pouco familiares & igual ou maior que 20 e menor que 40 \\
Metáforas não familiares & menor que 20 \\
\hline
\end{tabular}

4 expressões, isto é, menos de $5 \%$ do total, foram julgadas familiares por menos da metade dos participantes: "Alguns vizinhos são sapos" (familiar a 41,98\%), "Alguns carros são abacaxis" (40,74\%), "Algumas explicações são véus" (39,51\%) e a menos familiar ao grupo, "Alguns indivíduos são avestruzes" (37,04\%). A grande maioria, 75 das 84 expressões (89\% do total) foi julgada familiar por $60 \%$ ou mais dos participantes: desde aquelas que pareceram familiares a pouco mais da metade do grupo, por exemplo, "Alguns pensadores são águias" (60,49\%) e "Algumas amigas são camaleões" $(64,02 \%)$ às que soaram familiares a todos, p. ex.: "Algumas sogras são cobras" (100\%) e "Algumas mulheres são furacões" (100\%). Essa maioria abarcou as metáforas ranqueadas "familiares" e "muito familiares", pré-requisito da seleção dos estímulos do experimento de leitura automonitorada a se realizar na fase seguinte da pesquisa.

Contudo, decidimos elevar o nível de corte para $85 \%$ de respostas positivas (SIM) nos julgamentos da familiaridade das expressões, preservando 59 (ou 70\%) das 84 candidatas à seleção para compor o conjunto de estímulos do experimento de leitura automonitorada previsto. Sendo assim, as expressões metafóricas selecionadas foram julgadas familiares por $85 \%$ dos participantes, por exemplo, desde "Alguns políticos são raposas" $(85,19 \%)$, passando por "Alguns professores são carrascos" (98,77\%), até aquelas que alcançaram a unanimidade no grupo, p. ex.: "Alguns motoristas são lesmas" (100\%) e "Alguns músicos são feras" (100\%).

\footnotetext{
9 “As expressões abaixo lhe são familiares? Você já as leu ou ouviu? Marque SIM (se for familiar) ou NÃO (se não for familiar)" (cf. excerto do formulário de "Familiaridade", Figura 1).
} 
Tabela 2 - Ratings de Aptness no Experimento 2

\begin{tabular}{l|c}
\hline \multicolumn{1}{c|}{ Ratings das expressões } & Notas (de 1 a 5) $^{10}$ \\
\hline Metáforas very high-apt & 5 \\
Metáforas high-apt & 4 \\
Metáforas moderate-apt & 3 \\
Metáforas low-apt & 2 \\
Metáforas very low-apt & 1 \\
\hline
\end{tabular}

O ranqueamento em Aptness, de acordo com as notas de 1 a 5 dadas pelos participantes do Experimento 2 à eficácia das expressões, resultou nos ratings: very low-apt, low-apt, moderate-apt, high-apt e very high-apt, reunidos na Tabela 2.

Nenhuma das 84 expressões mereceu, dos participantes do Experimento 2, nota igual ou menor que $2 \mathrm{em}$ Aptness, redundando em não se ter, no conjunto, metáforas de ratings low-apt e very-low apt. E apenas 6 , ou $7 \%$ do total, receberam notas menores que 4 , caracterizadas como moderate-apt, a saber: "Alguns carros são abacaxis" (com a média 3,94), "Alguns estudantes são traças" (com 3,89), "Algumas explicações são véus" $(3,86)$, "Alguns vizinhos são sapos" $(3,77)$ e as duas de rating mais baixo, "Alguns humanos são canários $(3,65)$ e "Alguns indivíduos são avestruzes" $(3,57)$. Em matéria de "eficácia”, a quase totalidade das expressões, 78 ou cerca de $93 \%$, recebeu notas entre 4 e 5 , circunscrevendo a maioria aos ratings mais altos, high-apt ou very highapt, p. ex.: "Alguns viciados são zumbis" (com a média 4,08), "Alguns advogados são tubarões" $(4,32)$, "Algumas estradas são serpentes" $(4,35)$, "Alguns cunhados são malas" (4,72), "Algumas mães são leoas" $(4,82)$ e aquela que chegou mais perto de alcançar a nota máxima, "Algumas meninas são gatas" $(4,91)$.

Apesar das notas altas dadas à maioria das expressões, aplicamos, aqui, o rigor adotado antes, elevando para 4,5 o nível de corte nos ratings de Aptness das metáforas, preservando então 61 das 84 (ou 73\%) das candidatas a estímulos do experimento de leitura automonitorada previsto.

10 "Dê uma nota de 1 a 5 a cada uma das expressões abaixo, avaliando a sua eficácia em transmitir o significado que pretendem transmitir" (cf. excerto do formulário de "Aptness", Figura 2). 
Portanto, as expressões metafóricas selecionadas foram aquelas de rating igual ou maior do que 4,5, p. ex.: "Alguns policiais são gorilas" $(4,54)$, "Alguns pais são bananas" $(4,67)$, passando por "Alguns trabalhos são prisões" $(4,71)$, "Algumas modelos são aviões" $(4,8)$ até as que estiveram a ponto de alcançaram a unanimidade no grupo, tais como "Alguns lutadores são touros" $(4,89)$ e "Alguns mestres são espelhoo" (4,89).

As estimativas médias de "Convencionalidade", obtidas a partir dos resultados dos Experimentos 1 e 2 traduziu-se nos ratings: "metáforas novas", "metáforas pouco convencionalizadas", "metáforas medianamente convencionalizadas", "convencionalizadas" e "metáforas altamente convencionalizadas", reunidos na Tabela 3. As estimativas com respeito à "Convencionalidade" coletadas nos Experimentos 1 e 2 foram reunidas em estimativas médias, ponderadas em relação ao número de participantes de cada um deles, com o objetivo de tirar proveito da totalidade das observações. A adoção do mesmo nível de corte (85\%) utilizado para selecionar expressões com base em familiaridade, restringiu aqui os estímulos do experimento de leitura automonitorada previsto às expressões altamente convencionalizadas.

Tabela 3 - Ratings de "Convencionalidade" nos Experimentos 1 e 2

\begin{tabular}{ll}
\hline \multicolumn{1}{c|}{ Ratings das expressões } & \multicolumn{1}{c}{ Respostas congruentes $(\%)^{11}$} \\
\hline Metáforas altamente convencionalizadas & entre 80 e 100 \\
Metáforas convencionalizadas & igual ou maior que 60 e menor que 80 \\
Metáforas medianamente convencionalizadas & igual ou maior que 40 e menor que 60 \\
Metáforas pouco convencionalizadas & igual ou maior que 20 e menor que 40 \\
Metáforas novas & menor que 20 \\
\hline
\end{tabular}

Desse modo, foram selecionadas 43 expressões do conjunto original, com o objetivo de compor os estímulos do experimento de leitura automonitorada a se realizar na fase seguinte da pesquisa. Admitiramse, nessa seleção: metáforas "muito familiares" (em ao menos $85 \%$ dos julgamentos dos participantes do Experimento 1), metáforas very high-apt (de rating igual ou superior a 4,5 obtido no ranqueamento do

11 "[...] escolha uma palavra que você acredita que capture o significado da expressão" (cf. excertos dos formulários de "Familiaridade" e de "Aptness", Figura 1 e Figura 2, respectivamente). 
Experimento 2; e "altamente convencionalizadas" (em 85\% ou mais das estimativas médias nas avaliações dos participantes dos Experimentos 1 e 2, todas reunidas na Tabela 4 .

Tabela 4 -As 43 expressões selecionadas nos Experimentos 1 e 2

\begin{tabular}{|c|c|c|c|}
\hline As 43 expressões selecionadas & Familiaridade & Aptness & Convencionalidade \\
\hline Alguns políticos são raposas. & $85,19 \%$ & 4,67 & $97,45 \%$ \\
\hline Algumas crianças são anjos. & $98,77 \%$ & 4,77 & $89,83 \%$ \\
\hline Alguns chefes são toupeiras. & $92,59 \%$ & 4,66 & $94,92 \%$ \\
\hline Alguns seguranças são armários. & $93,83 \%$ & 4,76 & $95,56 \%$ \\
\hline Algumas modelos são aviões. & $97,53 \%$ & 4,8 & $98,73 \%$ \\
\hline Alguns pais são bananas. & $92,59 \%$ & 4,67 & $97,45 \%$ \\
\hline Alguns maridos são cavalos. & $96,30 \%$ & 4,68 & $100,00 \%$ \\
\hline Algumas sogras são cobras. & $100,00 \%$ & 4,82 & $99,36 \%$ \\
\hline Alguns meninos são diabos. & $98,77 \%$ & 4,67 & $96,84 \%$ \\
\hline Algumas modas são febres. & $96,30 \%$ & 4,72 & $96,19 \%$ \\
\hline Algumas senhoras são flores. & $91,36 \%$ & 4,68 & $99,37 \%$ \\
\hline Algumas mulheres são furacões. & $100,00 \%$ & 4,81 & $98,11 \%$ \\
\hline Algumas meninas são gatas. & $100,00 \%$ & 4,91 & $100,00 \%$ \\
\hline Algumas adolescentes são girafas. & $92,59 \%$ & 4,63 & $99,36 \%$ \\
\hline Alguns cordeiros são lobos. & $91,36 \%$ & 4,68 & $96,83 \%$ \\
\hline Algumas mães são leoas. & $97,53 \%$ & 4,82 & $98,11 \%$ \\
\hline Alguns motoristas são lesmas. & $100,00 \%$ & 4,85 & $98,73 \%$ \\
\hline Alguns genros são sanguessugas. & $91,36 \%$ & 4,66 & $98,73 \%$ \\
\hline Alguns avós são santos. & $86,42 \%$ & 4,65 & $87,97 \%$ \\
\hline Algumas tias são vitrolas. & $90,12 \%$ & 4,72 & $98,09 \%$ \\
\hline Algumas avós são corujas. & $98,77 \%$ & 4,73 & $98,11 \%$ \\
\hline Alguns cunhados são malas. & $97,53 \%$ & 4,72 & $96,83 \%$ \\
\hline Alguns músicos são feras. & $100,00 \%$ & 4,84 & $100,00 \%$ \\
\hline Algumas motos são foguetes. & $92,59 \%$ & 4,85 & $99,37 \%$ \\
\hline Alguns cozinheiros são porcos. & $97,53 \%$ & 4,85 & $94,33 \%$ \\
\hline Alguns locutores são papagaios. & $92,59 \%$ & 4,72 & $96,20 \%$ \\
\hline Algumas atitudes são máscaras. & $85,19 \%$ & 4,61 & $92,42 \%$ \\
\hline Algumas provas são torturas. & $98,77 \%$ & 4,81 & $100,00 \%$ \\
\hline Alguns botequins são chiqueiros. & $95,06 \%$ & 4,85 & $96,81 \%$ \\
\hline
\end{tabular}




\begin{tabular}{llll} 
Alguns professores são carrascos. & $98,77 \%$ & 4,87 & $96,20 \%$ \\
Algumas celebridades são antas. & $88,89 \%$ & 4,75 & $99,36 \%$ \\
Alguns fumantes são chaminés. & $96,30 \%$ & 4,86 & $97,47 \%$ \\
Alguns barracos são fornos. & $93,83 \%$ & 4,66 & $98,72 \%$ \\
Alguns caminhoneiros são tartarugas. & $95,06 \%$ & 4,85 & $98,72 \%$ \\
Algumas casas são fornalhas. & $95,06 \%$ & 4,72 & $97,47 \%$ \\
Algumas garotas são violões. & $95,06 \%$ & 4,8 & $97,44 \%$ \\
Alguns amigos são pilares. & $87,65 \%$ & 4,77 & $96,84 \%$ \\
Algumas torcidas são quadrilhas. & $92,59 \%$ & 4,63 & $89,89 \%$ \\
Algumas críticas são coices. & $92,59 \%$ & 4,72 & $94,30 \%$ \\
Alguns lutadores são touros. & $93,83 \%$ & 4,89 & $98,08 \%$ \\
Alguns mestres são espelhos. & $93,83 \%$ & 4,89 & $98,73 \%$ \\
Alguns trabalhadores são formigas. & $92,59 \%$ & 4,62 & $86,08 \%$ \\
Algumas vizinhas são moscas. & $93,83 \%$ & 4,51 & $95,53 \%$ \\
\hline
\end{tabular}

\section{Experimento 3: leitura automonitorada de metáforas do PB}

O experimento de leitura automonitorada (self-paced, non-cumulative, moving-window reading) objetivou evidenciar o processamento direto, sustentado pelo modelo teórico de Class-inclusion (GLUCKSBERG; KEYSAR, 1990), de metáforas do PB muito familiares, very high-apt e altamente convencionalizadas, selecionadas nos norming studies que realizamos, observando-se os tempos de leitura sobre o locus do "Problema do Reconhecimento" do significado metafórico, isto é, o veículo de cada uma das expressões (p. ex.: "um furacão" quando "Irene é um furacão" demandava interpretação metafórica). Foram registrados também os tempos de leitura de fragmentos correspondentes, p. ex.: "um furacão" quando "Irene é um furacão" tinha interpretação literal, e ainda os tempos de leitura de fragmentos-controle, p. ex.: "uma jovem" em declarações literais de inclusão em classe, no caso, "Irene é uma jovem".

Participantes: 66 voluntários participaram do experimento: 20 homens e 46 mulheres, com idade média de 27 anos. 35 foram recrutados entre os estudantes do Curso de Graduação em Letras da Universidade Federal Fluminense e 3 eram funcionários administrativos da instituição, esses, com nível superior completo de escolaridade. 28 eram estudantes de diversos cursos da Universidade Severino Sombra (Enfermagem, 
Engenharia de Produção, Engenharia Química, Medicina e Psicologia). Desses, 24 eram graduandos e 4 tinham Especialização.

Materiais: 9 trincas de parágrafos (transcritos no Apêndice), igualmente divididos em 11 fragmentos / sintagmas, foram preparadas para acomodar: no tipo 1: expressões do tipo "X é um Y" construídas a partir das metáforas que foram selecionadas nos pré-testes, p. ex.: "Irene é um furacão", construída a partir de "Algumas mulheres são furacões" (cf. Tabela 4); no tipo 2: expressões de significado literal do mesmo tipo (X é um Y), p. ex.: "Irene é um furacão", construída a partir do que se apurou sobre o furacão Irene, que assolou o Caribe e os EUA em 2011; e no tipo 3: declarações de inclusão em classe do mesmo tipo (X é um Y), p. ex.: "Irene é uma jovem", categorizando o tópico da expressão. Nos contextos do tipo 1, as expressões " $\mathrm{X}$ é um Y" demandavam interpretações metafóricas; nos do tipo 2, as mesmas expressões (X é um Y) pediam interpretações literais; e nos do tipo 3, "X é um Y" eram usuais declarações literais de inclusão em classe. Os fragmentos críticos das expressões - "um Y" em todas - metafóricas, literais e declarações literais de inclusão, foram balanceados em número de sílabas, 4; e em tipo e número de número de constituintes, "Det + N" (nos exemplos, respectivamente, "um furacão", "um furacão", "uma jovem"). E, ao final da leitura de cada um dos parágrafos, os participantes responderam a uma pergunta acerca do conteúdo lido, pressionando os botões correspondentes a SIM ou Não na caixa de botões acoplada ao dispositivo de exibição dos estímulos. As barras nos exemplos abaixo limitam, no papel, os 11 fragmentos apresentados em cada uma das janelas de leitura, na cadência imposta por cada um dos participantes ao realizar a leitura dos parágrafos.

Contexto do tipo 1: demandando interpretação metafórica Com muita frequência, / mulheres brasileiras / trabalham fora, / têm filhos / e estudam. / Irene é / um furacão / que empolga / todo mundo / no trabalho, em casa / e na faculdade.

Contexto do tipo 2: demandando interpretação literal

Com muita frequência, / fenômenos naturais / recebem nomes / de gente / dos mais comuns. / Irene é / um furacão / que assolou / o Caribe / e o leste dos EUA / em 2011. 
Contexto do tipo 3: demandando interpretação de declaração de inclusão em classe

Com muita frequência, / mulheres brasileiras / trabalham fora, / têm filhos / e estudam. / Irene é / uma jovem / que empolga / todo mundo / no trabalho, em casa / e na faculdade.

Os estímulos foram distribuídos (within-subjects, contrabalanceados em latin square) de modo que os participantes leram parágrafos em todas as 3 condições (lendo 3 estímulos por condição e jamais lendo o mesmo estímulo em mais de uma condição). Foram intercalados entre os 9 parágrafos-alvo outros 18 parágrafos, distrativos e a ordem de apresentação do total de 27 aleatorizada a cada sessão com cada um dos participantes. As perguntas após cada um dos parágrafos-alvo demandaram dos participantes, aproximadamente, tantas respostas SIM quantas NÃO.

Procedimentos: Em sessões individuais, cada um dos participantes leu os estímulos, fragmento a fragmento, apresentados, sob o seu comando, na tela de um microcomputador Apple, pressionando "o botão de passar a tela" de uma caixa de botões acoplada ao dispositivo. Para isso, a apresentação dos estímulos obedeceu a um protocolo construído em PsyScope, de modo a gravar os tempos de leitura e as respostas dos participantes. Antes de cada sessão, garantiu-se ao participante um breve treinamento, constando da leitura de 4 estímulos, com o fim de familiarizá-lo com o manuseio do equipamento e a rotina do experimento. Aos estudantes dos cursos de graduação foi oferecido um certificado de participação em atividade complementar aos estudos que eles(as) estivessem desenvolvendo. E, ao final de todas as sessões, os participantes puderam conhecer os objetivos do experimento e ter esclarecidas dúvidas que eventualmente tivessem.

Hipótese: De acordo com o modelo teórico de Class-inclusion (GLUCKSBERG; KEYSAR, 1990), as metáforas do PB muito familiares altamente convencionalizadas, e very high-apt selecionadas nos norming studies realizados devem ser processadas diretamente, sem a intermediação da derivação do significado literal, tal qual o são declarações literais de inclusão em classe. Alternativamente, de acordo com o chamado Modelo Pragmático Padrão, as mesmas metáforas devem ser processadas indiretamente, a partir da derivação do significado literal da expressão e sua rejeição no contexto do enunciado. 
Predições: Consequentemente à hipótese de pesquisa, de processamento direto de metáforas muito familiares, altamente convencionalizadas e high-apt, não se esperam diferenças significativas entre os tempos de leitura dos veículos dessas metáforas e os dos SNs correspondentes, tanto nas expressões equivalentes de significado literal quanto nas declarações literais de inclusão em classe. Prevalecendo o processamento indireto, devem-se observar tempos médios de leitura dos veículos das metáforas significativamente maiores do que os dos mesmos SNs-alvo de interpretação literal e os SNs-alvo nas declarações literais de inclusão em classe.

\subsection{Análise dos Resultados do experimento de leitura automonitorada}

Adotamos, aqui, o rigor metodológico que, nas críticas de Janus e Bever (1985), falta à literatura de até então, tanto ao sustentar quanto ao refutar o processamento indireto da metáfora que segue o Modelo Pragmático Padrão. Para tanto, dividimos os estímulos em sintagmas e medimos os tempos de leitura $(R T S)$ sobre o locus do "Problema do Reconhecimento" do significado metafórico, os veículos das metáforas. Mas, diferentemente de Janus e Bever (1985), cujos achados sugerem que metáforas novas são processadas indiretamente, a parir da derivação do significado literal da expressão, obtivemos resultados que oferecem sustentação à hipótese do processamento direto de metáforas convencionalizas, familiares e high-apt. De fato, Janus e Bever (1985, p. 485) admitem a possibilidade de processamento direto, do que eles chamam de frozen metaphors e aparentemente não foram outros os nossos achados no PB.

Contrariando as predições associadas à hipótese de processamento indireto nos termos do Modelo Pragmático Padrão, os participantes do experimento de leitura automonitorada que nós conduzimos não despenderam significativamente mais tempo na leitura dos veículos das metáforas, p. ex., "um furacão", em "Irene é um furacão", do que na leitura dos mesmos SNs em expressões de interpretação literal, p. ex., "Irene é um furacão", referindo o furacão que, em 2011, assolou o Caribe. E nem na leitura dos SNs correspondentes nas declarações literais de inclusão em classe, p. ex.: "Irene é uma jovem", sugerindo, assim, a validade da hipótese de processamento direto via Class-inclusion / Dual reference de Glucksberg e Keysar (1990), como demonstram os RTs médios reunidos na Tabela 5 . 
Tabela 5 - Tempos médios de leitura $(R T s$ em $\mathrm{ms})$ dos fragmentos críticos (em destaque) nas condições: Literal, Metafórico e Declaração Literal de Inclusão em Classe (DLIC)

\begin{tabular}{l|ll}
\hline Contextos & $R T S$ & Exemplos (extratos dos parágrafos) \\
\hline Literal & 954,25 & $\begin{array}{l}{[\ldots] \text { fenômenos naturais recebem nomes de gente. Irene é }} \\
\text { um furacão que assolou o Caribe }[\ldots] .\end{array}$ \\
Metafórico & 925,84 & $\begin{array}{l}{[\ldots] \text { mulheres brasileiras trabalham fora, têm filhos e }} \\
\text { estudam. Irene é um furacão que empolga todo }[\ldots] . \\
{[\ldots]}\end{array}$ \\
DLIC & 867,89 & \begin{tabular}{l} 
estudam. Irene é uma jovem que empolga todo $[\ldots]$. \\
\hline
\end{tabular}
\end{tabular}

Em nenhuma das 3 condições, Literal, Metáfora e Declaração Literal de Inclusão em Classe (DLIC), os $R T s$ dos fragmentos críticos apresentaram distribuição normal (na condição Literal, Estatística Kolmogorov-Smirnov $=0,14, \mathrm{p}<, 05$; na condição Metáfora, KolmogorovSmirnov $=0,12, p<, 05$; e na condição DLIC, Kolmogorov-Smirnov=0,12, $\mathrm{p}<, 05)$. Além disso, não se mostraram diferenças significativas nas Comparações Múltiplas entre as condições, DLIC-Literal, DLICmetáfora, Literal-Metáfora na análise estatística por sujeito (KruskalWallis $\mathrm{X} 2(2)=2,95, \mathrm{p}>, 05)$ e na análise por item (Kruskal-Wallis $\mathrm{X} 2(2)=3,55, \mathrm{p}>, 05)$. O Poder do Teste utilizado foi estimado em $70 \%$, capaz de avaliar diferenças de, no mínimo, 200 milissegundos (ms) entre os RTS dos fragmentos críticos das condições, diferenças como as que Janus e Bever (1985) relataram e que aqui não apareceram. ${ }^{12}$

\footnotetext{
${ }^{12}$ A natureza epistemológica de achados como os nossos, que se baseiam na falta de diferenças estatisticamente significativas entre as condições experimentais, tem sido questionada, tradicionalmente, nos termos do chamado argumentum ad ignorantiam (em inglês, the absence of evidence is not evidence of the absence). A evidência de ausência, na tradição que remonta ao ceticismo de Sextus Empiricus (século II), deve ser considerada falaciosa, como ausência de evidência que apenas pode não ter sido encontrada. Entretanto, cresce em importância a visão que não contempla com a pecha de falácia alguns casos em que uma proposição é presumida verdadeira simplesmente porque não pode ser provada falsa, ou é falsa porque não pode ser provada verdadeira (WALTON, 1992, p. 381-4). Admitem-se entre tais casos circunstâncias em que evidências conclusivas não se mostram apesar de perseguidas; e se presume verdadeira ou falsa a proposição que expressa a falta desses resultados, ainda que provisoriamente, tendo em vista a possiblidade de futuras refutações (p. 383). Sendo assim, alegamos
} 
As respostas dos participantes às perguntas sobre o conteúdo dos parágrafos atestaram, satisfatoriamente, o envolvimento dos indivíduos na realização da tarefa proposta. Considerando a sua totalidade (66), observou-se esmagadora maioria (94\%) de respostas corretas. Ou ainda, aproximadamente $99 \%$ dos participantes responderam corretamente a $90 \%$ das perguntas, permitindo que não se atribuam os resultados à falta de atenção dos leitores ou a dificuldades de compreensão dos estímulos.

A diferença estatisticamente não significativa (apenas $28,4 \mathrm{~ms}$ ) entre o tempo médio de leitura ( $R T$ médio) dos veículos das metáforas e o dos mesmos SNs interpretados literalmente é sugestiva de que os significados metafóricos familiares, high-apt e convencionalizados (assim julgados nas respostas off-line dos participantes dos norming studies) acham-se, de fato, "disponíveis" ao se dar a estruturação on-line das expressões predicativas e sua interpretação em contextos apropriados. Em relação a essa diferença (estatisticamente não significativa, de $28 \mathrm{~ms}$, repetimos), pode-se indagar se causaram aos participantes alguma "estranheza" e dificuldade de interpretar as expressões literais que, nos estímulos utilizados, atribuíam "nomes de gente" a entes não humanos, animados ou inanimados, e.g., "Irene é um furacão" no parágrafo "[...] fenômenos naturais recebem nomes de gente. Irene é um furacão que assolou o Caribe [...]" (cf. Apêndice, para os demais). Esse mesmo RT médio dos SNs de interpretação literal também se afastou $(86,36 \mathrm{~ms}$, diferença essa que também não se revelou estatisticamente significativa) do $R T$ médio de leitura dos SNs das declarações de inclusão em classe, p. ex., "Irene é uma jovem", que são do repertório dos falantes do PB enquanto conhecimento semântico consolidado. Se, então, algumas expressões literais causaram "estranhamento" (e expressões literais não

ser esse o caso das diferenças entre os $R T s$ dos segmentos críticos nas condições (como Hipótese Alternativa) que não se revelaram no experimento que conduzimos, ensejando a defesa - ao menos presuntiva, nos termos de Walton - da Hipótese de Pesquisa. Em reforço à presunção de que não são falaciosos os achados experimentais que obtivemos, aduzimos que, se, por um lado, a ausência de diferenças significativas entre os $R T_{s}$ dos segmentos críticos nas 3 condições pode ser parafraseada em termos da não rejeição da Hipótese Nula, por outro, o Poder do Teste utilizado no tratamento estatístico dos dados, estimado em $70 \%$, seria capaz de surpreender diferenças de, no mínimo, 200ms como aquelas que Janus e Bever (1985) relataram no processamento de metáforas novas, e, portanto, responder ao desafio de se estar cometendo, aqui, o erro do tipo II, de não rejeitar $\mathrm{H}_{0}$ falsa. (COOLICAN, 2014, p. 427-8). 
deveriam causar qualquer um), cabe alegar que o efeito ao confrontar, $\mathrm{p}$. ex., "Fernanda é uma lesma", no parágrafo "Em certas culturas, animais exóticos são adotados e ganham apelidos. Fernanda é uma lesma que habita um viveiro na casa de criadores nas Filipinas", deve-se, em tais casos, à "infelicidade" pragmática da declaração literal e não à violação das condições de verdade da sentença (cf. MATTHEWSON, 2004, p. 409). ${ }^{13}$ E verdade que, assim, se estaria estendendo a exemplares dos chamados enunciados "consta(ta)tivos" problemas, em princípio, inerentes aos "performativos", mas não sem algum aval da literatura. Ao menos para Gerken (1994, p. 78), ao "descrever", "explicar" e "teorizar" também nos comprometemos em atividades performativas, o que equivale a afirmar que seria mais adequado considerar "constativo" ou "descritivo" como caso especial de "performativo". Em Petrey (1990), é possível verificar que até Austin (1962) reconheceu que a distinção (originalmente proposta por ele, Austin) era demasiado forte, inclinando-se por sua reavaliação nos termos acima. Em Grandesso (2006), é possível tomar contato com a literatura em língua portuguesa que contempla as visões aqui expostas.

No que diz respeito à hipótese do processamento direto de metáforas, voltamos aqui ao que importa destacar: que o $R T$ médio de leitura dos veículos das metáforas não diferiu significativamente do $R T$ médio dos mesmos SNs interpretados literalmente. E que, também, não diferiu significativamente do $R T$ médio dos SNs correspondentes nas declarações literais de inclusão em classe $(57,95 \mathrm{~ms})$, o que enseja a defesa da posição Glucksberg e Keysar (1990), de que metáforas são o que aparentam ser: declarações de inclusão em classe, categorias metafóricas que recebem os nomes dos veículos, que delas são membros prototípicos. A não observância nos dados do $\mathrm{PB}$ aqui relatados de diferenças significativas entre os $R T s$ dos fragmentos críticos das condições sugere que metáforas familiares, high-apt e convencionalizadas sejam processadas como declarações de inclusão em classe, conforme o modelo de Class-inclusion (GLUCKSBERG; KEYSAR, 1990).

\footnotetext{
${ }^{13}$ Agradecemos à Dra. Luciana Sanchez Mendes, nossa colega no GEPEX - UFF, a sugestão de encaminhar na direção seguida acima a avaliação da instigante (embora estatisticamente marginal) diferença entre os tempos de leitura de SNs de interpretação literal e declarações literais de inclusão em classe.
} 
A ausência de diferenças significativas entre os $R T$ s que obtivemos poderia ser atribuída, talvez, à constituição da amostra. Entre os 66 participantes do experimento, não havia, de fato, equilíbrio na distribuição entre homens $(1 / 3)$ e mulheres (2/3); os indivíduos selecionados eram habitantes de diferentes cidades (duas, embora no mesmo estado); e cursavam ou haviam concluído os seus estudos em instituições de Ensino Superior que têm perfis diferentes uma, de ensino público, outra, instituição privada; eram estudantes de Graduação, incompleta (59) e completa (1) e com Especialização (6); e oriundos de cursos diversos.

Certamente, não se pretendeu ignorar o fato de que a compreensão de metáforas por indivíduos inseridos em contextos socioculturais diferentes pode diferir consideravelmente (para uma iniciação aos estudos de aspectos culturais envolvidos na compreensão de metáforas, vejam-se, por exemplo: Gibbs Jr. (2008) e Ortony (1993 [1979]) e referências por eles recomendadas). Tanto é assim que, na primeira fase da pesquisa, foram colhidos julgamentos a respeito de familiaridade, aptness e convencionalidade das expressões que deram origem aos estímulos utilizados no experimento de leitura automonitorada.

Ainda assim, passamos, a partir deste ponto, a sistematizar os achados do experimento de leitura automonitorada à luz do que se pode chamar de "uniformização" da amostra global. Ao restringir a amostra aos participantes que deram respostas corretas a todas as perguntas $(100 \%$ em vez de 94\%), e aos que eram estudantes da UFF, cursando o segundo período de Letras - chegou-se a 38 indivíduos cuja média de idade (antes, de 27,3 anos e, agora, 26,6 anos) alterou-se em menos de 1 ano; e a um subconjunto cuja proporção entre homens $(25 \%)$ e mulheres $(75 \%)$, reflete o público dos cursos de Letras no país. Considerando, então, a amostra "uniformizada", não se acham motivos de questionamentos dos resultados anteriormente mostrados (cf. Tabela 6), que não se mostraram divergentes dos anteriormente apontados (na Tabela 5, quando o total de 66 participantes foi considerado) e, portanto, não justificam outras conclusões. 
Tabela 6 - Tempos médios de leitura $(R T S)$ dos fragmentos críticos nas condições:

Literal, Metáfóra e Declaração Literal de Inclusão em Classe (em ms), com 66 e 38 participantes

\begin{tabular}{ccccc}
\hline & Literal & Metafórico & Controle \\
\hline 66 participantes & 954,25 & 925,84 & 867,89 \\
38 participantes & 1008,02 & 968,11 & 930,11 \\
\hline
\end{tabular}

Consequentemente, de uma maneira ou de outra, não se sustenta, nos resultados do experimento de leitura automonitorada realizado, a hipótese do processamento indireto de metáforas familiares, high-apt e convencionalizadas do $\mathrm{PB}$. Os $R T s$ médios não diferiram significativamente, sugerindo, assim, que os participantes, tanto os 66 da amostra original quanto os 38 do subconjunto dos que pertenciam a um grupo geográfico e socialmente mais homogêneo, compreenderam, sem dificuldades adicionais, em relação às mesmas expressões mesmas literais e declarações literais de inclusão em classe, as metáforas inseridas em contextos apropriados. Ao interpretar o significado metafórico de, p. ex., "Irene é um furacão" (porque aparentemente Irene agita o ambiente social, por onde quer que ela passe), os falantes nativos do PB da amostra selecionada não encontraram dificuldades, tanto quanto não encontraram em relação a interpretar literalmente "Irene é um furacão" (que assolou o Caribe). Bem como não encontraram dificuldades para interpretar o significado metafórico da mesma expressão maiores do que para interpretar "Irene é uma jovem", declaração literal de inclusão em classe (incluindo Irene na categoria das jovens), permitindo-nos inferir, como querem Glucksberg e cols. (GLUCKSBERG; KEYSAR, 1990; GLUCKSBERG, 1998; GLUCKSBERG, 2003), que compreenderam as metáforas tal qual compreenderam as declarações literais de inclusão em classe. 
Figura 3 - Propriedades associadas ao significado metafórico M-furacão de "furacão" no nível supraordenado e ao significado literal L-furacão "furacão" no nível básico da categoria

\begin{tabular}{|cl|}
\hline Nível Supraordenado da Categoria: & \\
propriedades M- furacão: & Muito impetuoso(a) \\
& Avassalador(a) \\
& Muito agitado(a) \\
& Muito Forte \\
Nível básico da Categoria: & \\
propriedades L- furacão: & Muito impetuoso(a) \\
& Avassalador(a) \\
& Muito agitado(a) \\
& Muito Forte \\
& Destruidor(a) \\
& Muito veloz \\
& Devastador(a) \\
& Tumultuador(a) \\
\hline
\end{tabular}

Assim como Glucksberg (1998, p. 41) estrutura, hierarquicamente, em 2 níveis de referência, em 2 níveis de referência, um básico e outro supraordenado ou metafórico, para dar conta de my lawyer is a shark ("meu advogado é um tubarão"), a categoria metafórica "furacão" achase ilustrada na Figura 3.

De acordo com o modelo Class-inclusion / Dual reference, diante da expressão "Irene é um furacão", o ouvinte / leitor acessa prontamente o significado metafórico do veículo da metáfora "furacão" convencionalizado (no PB, até dicionarizado. No modelo de Glucksberg e Keysar (1990) de processamento direto de metáforas por categorização, metáforas como, p. ex., "Irene é um furacão", seriam compreendidas como são compreendidas as declarações literais de inclusão em classe, às custas da inclusão de tópicos de categorias preexistentes, criadas a partir de veículos convencionalizados.

\section{Conclusões}

Os resultados dos experimentos realizados sustentam a hipótese defendida por Glucksberg e Keysar (1990), de processamento direto de metáforas familiares, high-apt e cujos veículos se acham convencionalizados, conforme o modelo Class-inclusion. Foram medidos os RTs sobre os fragmentos críticos das expressões, encaixadas em contextos apropriados, e não se observou diferença significativa entre 
os $R T S$ dos veículos das metáforas e das expressões literais equivalentes. Tampouco se observou diferença significativa entre os $R T s$ médios dos veículos das metáforas e de declarações literais de inclusão em classe, o sugere que o processamento das metáforas em questão deu-se conforme o modelo Class-inclusion / Dual reference (GLUCKSBERG; KEYSAR, 1990).

Importa assinalar que aqui não se cogitou estender a ideia de processamento direto via Class-inclusion a categorias que não as preexistentes, como ambiciona Glucksberg (2008). Para Glucksberg (2008), a convencionalidade de "veículos" decorre necessariamente do seu uso em expressões bem construídas. E, sendo assim, metáforas highapt, ainda que novas, seriam interpretadas como declarações de inclusão em classe. No futuro, tal hipótese poderá (e deve) ser devidamente testada.

Apesar do ineditismo, o presente estudo não ultrapassa os limites que, desde o início, se impôs: o de avaliar no PB o processamento de metáforas convencionalizadas, familiares e high-apt. Fica ainda à espera do interesse de pesquisas que ainda hão de vir, o estudo do processamento de metáforas do PB com o auxílio do rastreamento de movimentos oculares na compreensão de metáforas e, é claro, a extração de potenciais evocados durante a audição / leitura de metáforas do PB e investigações com base em neuroimagem.

\section{Agradecimentos}

Agradecemos aos pares anônimos pelas indicações de aspectos do texto que mereceram reformulação. Ao Parecerista 1, no trato da transição para os objetivos, hipótese e predições do experimento de leitura auto-monitorada. Ao Parecerista 2, por pleitear (sem exigir) o uso de equivalentes em português de termos em inglês que se acham consagrados na literatura internacional, o que virá, cada vez mais, à medida que o campo de processamento de metáfora se consolidar entre nós. E, finalmente, ao organizador do volume por nos impelir à necessária discussão (veja-se a nota 12) dos achados que relatamos, tendo em vista as ideias em torno do chamado argumentum ad ignorantiam. 


\section{Referências}

AULETE, Caldas. Aulete Digital: o dicionário da língua portuguesa na internet. Versão online. Disponível em: <http://www.aulete.com.br/>. Acesso em: 16 set. 2015.

AUSTIN, J.L. How to do things with words. Cambridge, Mass.: Harvard University Press, 1962.

BLASKO, D.; CONNINE, C.M. Effects of familiarity and aptness on metaphor processing. The Journal of Experimental Psychology: Learning, Memory, and Cognition, Washington, v. 19, p. 295-308, 1993. https://doi. org/10.1037/0278-7393.19.2.295.

BOWDLE, B. F.; GENTNER, D. The career of metaphor. Psychological Review, American Psychological Association, v. 112, n. 1, p. 193-216, 2005. https://doi.org/10.1037/0033-295x.112.1.193.

CHIAPPE, D.; KENNEDY, J. M.; SMYKOWSKI, T. Reversibility, aptness, and the conventionality of metaphors and similes. Metaphor and Symbol, v. 18, n. 2, p. 85-105, 2003. https://doi.org/10.1207/ S15327868MS1802_2.

CLARK, H. H.; LUCY, P. Understanding what is meant from what is said: A study in conversationally conveyed requests. Journal of Verbal Learning and Verbal Behavior, Elsevier B. V., n. 14, p. 56-72, 1975.

COOLICAN, H. Research methods and statistics in psychology. $6^{\text {th }}$ ed. London; New York: Psychology Press; Taylor \& Francis Group, 2014.

CRAIG, Colette G. (Ed.). Noun classes and categorization: Proceedings of a symposium on categorization and noun classification, Eugene, Oregon, October 1983. John Benjamins Publishing Company, 1986.

DENNY, J. Peter. The semantic role of noun classifiers. Noun classes and categorization, p. 297-308, 1986.

DULCINATI, G.; MAZZARELLA, D.; POUSCOULOUS, N.; RODD, J. Processing metaphor: The role of conventionality, familiarity and dominance. UCL Working Papers in Linguistics, London, University College London, v. 26, p. 72-88. 2014.

FERREIRA, Aurélio Buarque de Hollanda. Miniaurélio: o Minidicionário da Língua Portuguesa. 6. ed. ver. ampl. Curitiba: Positivo, 2004. 
FERREIRA, Aurélio Buarque de Hollanda. Novo Aurélio século XXI: o dicionário da língua portuguesa. 3. ed. ver. ampl. Rio de Janeiro: Nova Fronteira, 1999.

FRASER, B. The interpretation of novel metaphors. In: ORTONY, A. (Ed.). Metaphor and thought. Cambridge: Cambridge University Press, p. 329-341, 1993. https://doi.org/10.1017/CBO9781139173865.017.

GARRET, J. Aristotle on metaphor. 2007. Disponível em: $<$ http://people. wku.edu/jan.garrett/401s07/arismeta.htm>. Acesso em: 6 dez. 2016.

GERKEN, L. A metrical template account of children's weak syllable omissions from multisyllabic words. Journal of Child Language, Cambridge, Cambridge University Press, v. 21, p. 565-584, 1994. https:// doi.org/10.1017/s0305000900009466.

GIBBS JR, R. W. Contextual effects in understanding indirect requests. Discourse Processes, v. 2, p. 1-10, 1979. https://doi. org/10.1080/01638537909544450.

GIBBS JR, R. W. The Cambridge Handbook of Metaphor and Thought. Cambridge: Cambridge University Press, 2008. https://doi.org/10.1017/ CBO9780511816802.

GIBBS JR, R. W. Your wish is my command: Convention and context in interpreting indirect requests. Journal of Verbal Learning and Verbal Behavior, Elsevier B. V., v. 20, p. 431-444, 1981.

GLUCKSBERG, S. How metaphors create categories - quickly. In: GIBBS JR, R. W. The Cambridge Handbook of Metaphor and Thought. Cambridge: Cambridge University Press, p. 67-83, 2008. https://doi. org/10.1017/CBO9780511816802.

GLUCKSBERG, S. The Psycholinguistics of metaphor. Trends in Cognitive Sciences, Elsevier, v. 7, n. 2, p. 92-96, 2003. https://doi. org/10.1016/S1364-6613(02)00040-2.

GLUCKSBERG, S. Understanding metaphors. Current Directions in Psychological Science, Cambridge, Cambridge University Press, v. 7, n. 2, p. 39-43, 1998.

GLUCKSBERG, S.; GILDEA, P.; BOOKIN, H. B. On understanding nonliteral speech: can people ignore metaphors? Journal of Verbal Learning and Verbal Behavior, Elsevier B. V., v. 21, p. 85-98, 1982. 
GLUCKSBERG, S.; KEYSAR, B. Understanding Metaphorical Comparisons: Beyond Similarity. Psychological Review, American Psychological Association, v. 97, n. 1, p. 3-18, 1990. https://doi. org/10.1016/S1364-6613(02)00040-2.

GRANDESSO, M. Sobre a reconstrução do significado: uma análise epistemológica e hermenêutica da prática clínica. 2. ed. São Paulo: Casa do Psicólogo, 2006.

GRICE, H. P. Logic and Conversation. In: COLE, P.; MORGAN, J. L. (Ed.). Syntax and Semantics. New York: Academic Press, 1975. [v. 3: Speech Acts, p. 41-58].

HAGE, P.; MILLER, W. R. 'Eagle' = 'bird': A note on the structure and evolution of Shoshoni ethnoornithological nomenclature. American Ethnologist, 3, p. 481-488, 1976. https://doi.org/10.1525/ ae.1976.3.3.02a00060.

HARRIS, R. J. Comprehension of metaphors: A test of the two-stage processing model. Bulletin of the Psychonomic Society, v. 8, n. 4, p. 312314, 1976. https://doi.org/10.3758/BF03335150.

HOUAISS, A.; VILLAR, M. S. Dicionário Houaiss da Língua Portuguesa. 3. ed. Rio de Janeiro: Objetiva, 2009.

JANUS, R. A.; BEVER, T. G. Processing of metaphoric language: an investigation of the three-stage model of metaphor comprehension. Journal of Psycholinguistic Research, Springer International Publishing A. G., v. 14, n. 5, p. 473-487, 1985.

JOHNSON, A.T. Comprehension of metaphors and similes: a reaction time study. Metaphor and Symbolic Activity, Lawrence Erlbaum Associates, Inc., v. 11, n. 2, p. 145-159, 1996.

JONES, L. L.; ESTES, Z. Roosters, robins, and alarm clocks: Aptness and conventionality in metaphor comprehension. Journal of Memory and Language, Elsevier, v. 55, n. 1, p. 18-32, 2006. https://doi.org/10.1016/j. jml.2006.02.004.

MATTHEWSON, L. On the methodology of semantic fieldwork. International Journal of American Linguistics, Chicago, University of Chicago, v. 70, n. 4, p. 369-415, Oct. 2004. 
MILLER, G. A. Images and models: similes and metaphors. In: ORTONY, A. (Ed.). Metaphor and thought. Cambridge: Cambridge University Press, p. 202-250, 1979.

MORISON, Benjamin. Sextus Empiricus. In: ZALTA, Edward N. (Ed.). The Stanford Encyclopedia of Philosophy. Stanford: Spring Edition, 2014. Disponível em: <https://plato.stanford.edu/archives/spr2014/entries/ sextus-empiricus/>. Acesso em: 1 mar. 2017.

ORTONY, A. Metaphor and thought. $2^{\text {nd }}$ edition. New York: Cambridge University Press, 1993 [1979]. https://doi.org/10.1017/ CBO9781139173865.

ORTONY, Andrew et al. Interpreting metaphors and idioms: Some effects of context on comprehension. Journal of verbal learning and verbal behavior, v. 17, n. 4, p. 465-477, 1978.

PETREY, S. Speech Acts and Literary Theory. New York; London: Routledge, 1990.

RIBEIRO, A. J. C.; RICCI, A.Q.; KENEDY, E. O processamento psicolinguístico da metáfora: um estudo inédito no português brasileiro. In: ENCONTRO NACIONAL DA ANPOLL (ENANPOLL), XXXI, 2016, Campinas. Poster. Campinas: UNICAMP, 2016.

RICCI, A. Q. O processamento psicolinguístico da metáfora: um estudo experimental no PB. 2016. 75f. Dissertação (Mestrado em Estudos de Linguagem) - Instituto de Letras, Universidade Federal Fluminense, 2016.

SEARLE, J. Metaphor. In: ORTONY, A. Metaphor and thought. $2^{\text {nd }}$ edition. New York: Cambridge University Press, 1993. p. 83-111. [1979]

SHINOFF, P. Demjanjuk war-crimes tribunal strikes deep fear among Jews. San Francisco Examiner, June 14, p. A8, 1987.

STROOP, J.R. Studies of interference in serial verbal reactions. Journal of Experimental Psychology, American Philosophical Association, v. 18, p. 643-662, 1935.

THIBODEAU, P. H.; DURGIN, F. H. Metaphor aptness and conventionality: A processing fluency account. Metaphor and Symbol, Francis \& Taylor Online, v. 26, p. 206-226, 2011. 
TRAGER, G. L. "Cottonwood-Tree", a south-western linguistic trait. International Journal of American Linguistics, 9, p. 117-118, 1938. https://doi.org/10.1017/CBO9781139173865.

TVERSKY, A. Features of similarity. Psychological Review, American Psychological Association, v. 84, p. 327-352, 1977. https://doi. org/10.1037/0033-295x.84.4.327.

WALTON, Douglas. Nonfallacious arguments from ignorance. American Philosophical Quarterly, v. 29, n. 4, Oct. 1992. Disponível em: <http:// dougwalton.ca/papers\%20in\%20pdf/92nonfallacious.pdf $>$. Acesso em: 1 mar. 2017. 


\section{Apêndice: Parágrafos experimentais do experimento cronométrico}

Os parágrafos experimentais e respectivas perguntas que se seguem estão organizados na sequência Literal / Metáfora / Declaração Literal de Inclusão em Classe, em cada trinca.

1. Com muita frequência, fenômenos naturais recebem nomes de gente dos mais comuns. Irene é um furacão que assolou o Caribe e o leste dos EUA em 2011.

Com muita frequência, mulheres brasileiras trabalham fora, têm filhos e estudam. Irene é um furacão que empolga todo mundo no trabalho, em casa e na faculdade.

Com muita frequência, mulheres brasileiras trabalham fora, têm filhos e estudam. Irene é uma jovem que empolga todo mundo no trabalho, em casa e na faculdade.

2. Excepcionalmente, móveis italianos têm qualidade e nome no mercado. Bérgamo é um armário que recebe dos clientes ótimas avaliações nos comentários.

Excepcionalmente, segurança de rua porta armas para ser respeitado. Bérgamo é um armário que trabalha com ajuda do porte avantajado e da força bruta.

Excepcionalmente, segurança de rua porta armas para ser respeitado. Bérgamo é um vigia que trabalha com ajuda do porte avantajado e da força bruta.

3. Em certas culturas, animais exóticos são adotados e ganham apelidos. Fernanda é uma lesma que habita um viveiro na casa de criadores nas Filipinas.

Costumeiramente, motoristas idosos guiam devagar sem razão no trânsito. Fernanda é uma lesma que atrasa a chegada no trabalho ou lazer quando usa carro.

Costumeiramente, motoristas idosos guiam devagar sem razão no trânsito. Fernanda é uma chofer que atrasa a chegada no trabalho ou lazer quando usa carro. 
4. Em certas famílias, bichos de estimação distanciam-se do padrão esperado. Tereza é uma cobra que só pica raramente e não tem qualquer veneno, segundo o dono.

Em certas famílias sogras problemáticas implicam muito com genros, sem motivos. Tereza é uma cobra que ataca sem aviso o marido da filha em qualquer lugar.

Em certas famílias sogras problemáticas implicam muito com genros, sem motivos. Tereza é uma sogra que ataca sem aviso o marido da filha em qualquer lugar.

5. Em alguns lugares, primatas em extinção ganham proteção de ONGs e pessoas. Samuel é uma fera que resiste na África à extinção dos gorilas até o momento.

Por todo o mundo, guitarristas famosos sobem em palcos ou tocam ao ar livre. Samuel é uma fera que fascina o público da banda de rock Skank há muitos anos.

Por todo o mundo, guitarristas famosos sobem em palcos ou tocam ao ar livre. Samuel é um músico que fascina o público da banda de rock Skank há muitos anos.

6. Em filmes infantis, grupos de felinos formam famílias felizes e saudáveis. Maria é uma gata que alegra as crianças na famosa animação Os Aristogatas. Em qualquer época, meninas sedutoras estão no centro de festas e baladas. Maria é uma gata que encanta os garotos em qualquer reunião de adolescentes.

Em qualquer época, meninas sedutoras estão no centro de festas e baladas. Maria é uma moça que encanta os garotos em qualquer reunião de adolescentes.

7. De tempos em tempos, animais adestrados ficam famosos em filmes de sucesso. Argento é um cavalo que estrela a história Cavaleiro Solitário na pele de Silver.

Em alguns lugares, maridos ciumentos podem agredir esposas sem punição. Anderson é um cavalo que recebeu até hoje apenas advertências por bater na mulher.

Em alguns lugares, maridos ciumentos podem agredir esposas sem punição. Anderson é um marido que recebeu até hoje apenas advertências por bater na mulher. 
8. Muito raramente, heroínas de filmes são veículos a motor femininos. Rochelle é um avião que atua no sucesso de animação da Disney chamado Aviões.

De modo esperado, modelos de beleza são convidadas a posar para fotos. Rochelle é um avião que desfila com sucesso nas capas de revistas e nas passarelas.

De modo esperado, modelos de beleza são convidadas a posar para fotos. Rochelle é uma jovem que desfila com sucesso nas capas de revistas e nas passarelas.

9. Para quase todos, produtos japoneses são tidos como muito bons e duráveis. Tagima é um violão que músicos destacados têm como referência de qualidade.

De modo habitual, garotas de biquíni são criticadas com rigor por mulheres. Tagima é um violão que revela destemor diante dos olhares de todas na praia. De modo habitual, garotas de biquíni são criticadas com rigor por mulheres. Tagima é uma moça que revela destemor diante dos olhares de todas na praia. 